\title{
Medical staff who use ionizing radiation at Ibn Rochd University Hospital Center of Casablanca, Morocco: evaluation of radiation protection knowledge
}

\author{
Lamia Hjiyej Andaloussi ${ }^{1, *}$, Hicham Harrass ${ }^{1}$, Hind Aschawa ${ }^{2}$, and Fatima Zahra Hlousse ${ }^{3}$ \\ ${ }^{1}$ Department of Biophysics, Faculty of Medicine and Pharmacy, Hassan II University. Casablanca, Morocco. \\ ${ }^{2}$ Department of Nuclear Medicine, Ibn Rochd UHC Casablanca, Morocco. \\ ${ }^{3}$ Faculty of Medicine and Pharmacy, Hassan II University. Casablanca, Morocco.
}

\begin{abstract}
Hospital activity of professionals who use ionizing radiation (IR) at work generates risks on their health. Good knowledge of radiation protection (RP) rules can contribute to minimize these risks. This descriptive and analytical study, carried out from March 25 to May 14, 2019 as a survey, focused on knowledge about IR and RP. It was intended for medical and paramedical staff from several departments of Ibn Rochd UHC in Casablanca. Among 135 surveyed workers, 83\% with median age of 31 years (21 to 54 years) participated. $65.17 \%$ of participants were physicians whose $76 \%$ were in training. $47 \%$ of respondents had a high global level of knowledge, with mean score of $6.6 / 10$. IR average score $(7.8 / 10)$ were better than RP average score $(6.23 / 10)$. The scores varied significantly according to RP education $(p<0.002)$ and home department $(p<0.002)$. RP score was more strongly correlated to RP education $\left(\eta^{2}=0.32\right)$ than to department membership $\left(\eta^{2}=0.14\right)$. Medical staff RP knowledge are insufficient. In order to improve workers' knowledge on $\mathrm{RP}$, and thereby protect their health, it would be desirable to set up systematic pre-hire training and continuing education programs as well as integrate a radiation safety officer into all departments operating under IR.
\end{abstract}

\section{Introduction}

Ibn Rochd University Hospital Center of Casablanca (UHCC) is a structure that has an important cutting-edge radiological equipment and provides an increased care activity. The patient is the first person exposed to ionizing radiations (IR) and must accept their side effects. However, medical personnel are also exposed to IR, they are therefore constrained by professional obligation and they must as far as possible avoid the disadvantages of these exposures for their health. Among workers professionally exposed to IR, followed by the Institute for Radiation Protection and Nuclear Safety (IRPNS) until 2014, medical staff represented the most common occupational category that exceeded the recommended annual dose limit for workers, set at $20 \mathrm{mSv} /$ year. This dose will not be exceeded if professional properly controls the use of IR. Besides, the medical personnel suffer from a significant lack of compliance with radiation protection rules and principles [1]. This situation could result from a lack of knowledge about the necessary means and attitudes to protect medical staff against the harmful effects of IR: Radiation Protection (RP).

Radiation Protection has three fundamental principles (Justification, Optimization and Limitation of radiation doses) [2], [3] which result from the general principle ALARA (As low As Reasonably achievable). This discipline appeals also to rules of protection, corresponding to each of the three categories of population: public, patients and workers, which are necessary for applying fundamental principles [4]. For an appropriate application of these three fundamental

*Corresponding author: lamia hjiyej@hotmail.com principles in order to minimize the exposure to IR, the workers should sufficiently master the IR effects and characteristics as well as the RP measures.

In this study, we aimed to assess the knowledge, of UHCC medical and paramedical workers who use radiations in their daily occupation, about their own radiation protection and to identify the lacks to fill, to ensure their safety at work.

\section{Materials and methods}

\subsection{Type of study and study population}

We have conducted a descriptive and an analytical transversal study proposing a multiple-choice questionnaire. It has been carried out from $25^{\text {th }}$ March 2019 to $14^{\text {th }}$ may 2019 , inside UHCC. Anonymous questionnaires were given to medical and paramedical personnel of central radiology (RC), $20^{\text {th }}$ August radiology (RA), radiology of emergencies (RU), radiation therapy (RTH) and nuclear medicine (NM) departments.

We included the medical and paramedical personnel that are daily working in the departments mentioned above and have given their consent to participate in this study. There were 135 workers including specialist doctors, interns and residents, technicians of Radiology, medical Physicists and nurses.

\subsection{Questionnaire}

The questionnaire was developed based on the literature data and recommendations from official bodies including International Atomic Energy Agency (IAEA) and the Moroccan Agency for Nuclear and Radiological 
Safety and Security (AMSSNuR)[5]. It consisted on 29 questions and divided into 4 sections:

- Socio-professional characteristics and training on RP

- Knowledge on IR characteristics and effects (IRK)

- Knowledge on general principles means of RP (RPK)

- Knowledge on IR and RP specific to each department (SK).

Three other questions were intended to collect the opinions of workers on the interest they have for continuing education in RP and the wish to benefit, and their expectations and needs in order to improve radiation protection in their departments.

The questionnaires were distributed by hand, and we considered as non-respondent any person who did not return the questionnaire or who did not answer the questionnaire after our third visit. We assured the participants that data collected would be confidential. A preliminary study was conducted among the professors of each department to assess any confusion on the issues. The comments made have been taken into account.

\subsection{Data processing and statistical analysis:}

Each correct answer was scored one point and a false or no answer was scored zero point. The obtained results were given as follows:

- Level of knowledge : We considered that the level of knowledge is high if the rate of correct responses is greater than $70 \%$, the level is moderate if $50 \%<$ rate $\leq 70 \%$ and it is low if rate $\leq 50 \%$.

- Score out of 10 (for example 13 correct answers out of 26 corresponded to a score of 5/10). We subdivided the global score (GS), which relates to all the questions, into a score concerning the knowledge of characteristics and effects of IR (IRKS), a score concerning the knowledge of principles and means of radiation protection (RPKS) and a score on the knowledge about IR and RP specific to each department (SKS).

Categorical variables were assessed by the chi-square test. The comparison between scores was assessed by ANOVA test supplemented by calculation of the correlation ratio. In case of significant differences, multiple comparisons were performed. Statistical analysis were performed using SPSS version 22 and a $p$ value $<0.05$ was considered significant.

\section{Results}

On a total of 135 questionnaires handed out, 112 have been completely filled and given back (response rate $83 \%$ ) (table 1). Fifty percent of responders were interns and residents, and radiology workers were the most numerous (67.13\% of respondents). Almost sixty percent of the participants had practiced during less than 5 years. Forty percent of participants reported being trained in radiation only during the educational curriculum and $26 \%$ said they had never been introduced to the radiation protection.
Table 1. Socio-professional characteristics of respondents

\begin{tabular}{|c|c|c|c|}
\hline & & $\mathbf{n}$ & $\%$ \\
\hline \multirow[t]{2}{*}{ Gender } & Female & 82 & 73.22 \\
\hline & Male & 30 & 26.78 \\
\hline \multirow{5}{*}{$\begin{array}{l}\text { Ocupational } \\
\text { category }\end{array}$} & Specialist doctor & 17 & 15.17 \\
\hline & Interns and residents & 56 & 50.00 \\
\hline & Radiation physicist & 5 & 4.40 \\
\hline & $\begin{array}{l}\text { Technicians of } \\
\text { radiology }\end{array}$ & 32 & 28.57 \\
\hline & Nurses & 2 & 1.80 \\
\hline \multirow{4}{*}{$\begin{array}{l}\text { Years } \\
\text { of practice }\end{array}$} & $<5$ years & 67 & 59.82 \\
\hline & 5 - 10 years & 28 & 25.00 \\
\hline & $10-20$ years & 16 & 14.28 \\
\hline & $>20$ years & 1 & 0.90 \\
\hline \multirow{3}{*}{$\begin{array}{l}\text { Departments } \\
\text { surveyed }\end{array}$} & Nuclear medicine & 21 & 18.75 \\
\hline & Radiology & 75 & 67.13 \\
\hline & Radiation therapy & 16 & 14.12 \\
\hline \multirow{4}{*}{$\begin{array}{l}\text { Education } \\
\text { in RP }\end{array}$} & No training & 29 & 25.89 \\
\hline & Educational curriculum & 45 & 40.17 \\
\hline & $\begin{array}{l}\text { Educational curriculum } \\
+ \text { other* education }\end{array}$ & 20 & 17.86 \\
\hline & $\begin{array}{l}\text { Other* education than } \\
\text { curriculum }\end{array}$ & 18 & 16.08 \\
\hline \multirow{2}{*}{$\begin{array}{l}\text { Continuing } \\
\text { professional } \\
\text { education }\end{array}$} & $\begin{array}{l}\text { Have received } \\
\text { continuing education }\end{array}$ & 6 & 5.30 \\
\hline & $\begin{array}{l}\text { Wish to receive a } \\
\text { continuing education }\end{array}$ & 86 & 76.78 \\
\hline
\end{tabular}

On 112 participants, concerning global knowledge (GK) across all questions, the level of knowledge was high for $47.32 \%$ of participants (figure 1) with a mean GS of $6.6 \pm 1.45$ (table 2).

Separate analysis of the questions regarding IR, RP and specific knowledge revealed that the level of knowledge was high for $74 \%$ of the participants concerning IRK, it was high for $39 \%$ of participants concerning RPK and for $56.25 \%$ of respondents concerning SK (figure 1).

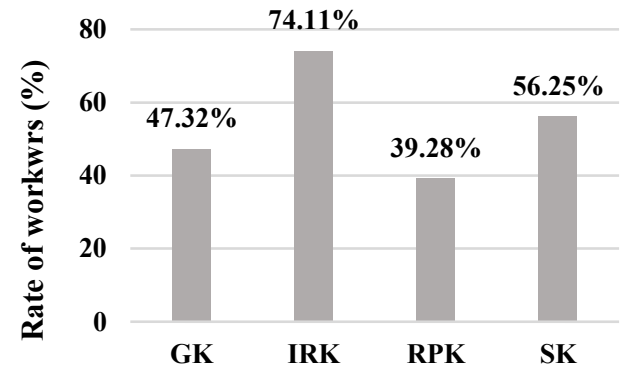

Fig. 1. Rate of participants with high level of global knowledge, IR, RP and specific knowledge.

The mean of the IRKS was $7.80 \pm 1.86$. It was better than the mean of the RPKS $(6.23 \pm 1.52)$ and that of the SKS $(7.05 \pm 2.34)$ (table 2). 
Table 2. Rates of workers with high level of Knowledge and mean scores among surveyed workers

\begin{tabular}{lcccc}
\hline & $\begin{array}{c}\text { Workers } \\
\text { Rates (\%) }\end{array}$ & $\begin{array}{c}\text { Mean score } \\
\pm \text { SD }\end{array}$ & Min & Max \\
\hline GK & 47.32 & $6.60 \pm 1.45$ & 2.70 & 8.80 \\
IRK & 74.11 & $7.80 \pm 1.86$ & 1.90 & 10.00 \\
RPK & 39.28 & $6.23 \pm 1.52$ & 2.74 & 8.43 \\
SK & 56.25 & $7.05 \pm 2.34$ & 0.00 & 10.00 \\
\hline
\end{tabular}

The comparison of knowledge levels and the comparison of scores showed no significant differences by occupational category or by years of practice. Contrarily, there were significant differences according to the belonging department and according to the radiation protection training received by the workers. Table 3 summarizes the p-values for these two tests and the correlation ratios $\left(\eta^{2}\right)$ for scores comparison.

The results of multiple comparisons for scores in IR and $\mathrm{RP}$ by department, revealed that workers in nuclear medicine department and those in radiation therapy department achieved significantly better scores in $\operatorname{IR}(9.02,8.99)$ and in $\operatorname{RP}(6.75,6.71)$ (tables 4 and 5).

Table 3. Statistical significance of ANOVA and chi-square tests

\begin{tabular}{|c|c|c|c|c|c|c|c|c|}
\hline & \multicolumn{2}{|c|}{ Global } & \multicolumn{2}{|c|}{ IR } & \multicolumn{2}{|c|}{$\mathbf{R P}$} & \multicolumn{2}{|c|}{ Specific } \\
\hline & Anova & Chi 2 & Anova & Chi 2 & Anova & Chi 2 & Anova & Chi 2 \\
\hline & $p\left(\eta^{2}\right)$ & $\mathbf{p}$ & $p\left(\eta^{2}\right)$ & p & $p\left(\eta^{2}\right)$ & $\mathbf{p}$ & $p\left(\eta^{2}\right)$ & $\mathbf{p}$ \\
\hline $\begin{array}{l}\text { Occupational } \\
\text { category }\end{array}$ & $\begin{array}{l}0.117 \\
(0.066)\end{array}$ & 0.349 & $\begin{array}{l}0.15 \\
(0.011)\end{array}$ & 0.390 & $\begin{array}{l}0.391 \\
(0.037)\end{array}$ & 0.123 & $\begin{array}{l}0.22 \\
(0.051)\end{array}$ & 0.194 \\
\hline Years of practice & $\begin{array}{l}0.855 \\
(0.071)\end{array}$ & 0.363 & $\begin{array}{l}0.830 \\
(0.008)\end{array}$ & 1 & $\begin{array}{l}0.453 \\
(0.007)\end{array}$ & 0.304 & $\begin{array}{l}0.531 \\
(0.020)\end{array}$ & 0.128 \\
\hline Department & $\begin{array}{l}<\mathbf{0 . 0 0 2} * \\
(0.190)\end{array}$ & $0.001 *$ & $\begin{array}{l}<\mathbf{0 . 0 0 2 *} \\
(0.244)\end{array}$ & $0.001 *$ & $\begin{array}{l}\text { 0.003* } \\
(0.140)\end{array}$ & $0.020 *$ & $\begin{array}{l}\text { 0.050* } \\
(0.082)\end{array}$ & $0.004 *$ \\
\hline Education in RP & $\begin{array}{l}<\mathbf{0 . 0 0 2} * \\
(0.230)\end{array}$ & $0.002 *$ & $\begin{array}{l}\mathbf{0 . 0 5 0 *} \\
(0.066)\end{array}$ & $0.029 *$ & $\begin{array}{l}<0.002 * \\
(0.320)\end{array}$ & $0.002 *$ & $\begin{array}{l}\text { 0.028* } \\
(0.081)\end{array}$ & $0.002 *$ \\
\hline
\end{tabular}

Table 4. Multiple comparisons of IR scores according to the belonging department ( $p$ value)

\begin{tabular}{lllllll}
\hline & NM & RC & RTH & RU & RA & score \\
\hline NM & & $\mathbf{0 . 0 0 *}^{*}$ & NS & $0.029^{*}$ & $0.00^{*}$ & $9.02 \pm 1.24$ \\
RTH & NS & $\mathbf{0 . 0 0 *}^{*}$ & & $\mathbf{0 . 0 3 5}^{*}$ & $\mathbf{0 . 0 0 *}$ & $8.99 \pm 0.69$ \\
RU & $\mathbf{0 . 0 2 9}$ & NS & $\mathbf{0 . 0 3 5 *}$ & & NS & $7.79 \pm 1.76$ \\
RA & $\mathbf{0 . 0 0 *}$ & NS & $\mathbf{0 . 0 0 *}$ & NS & & $6.99 \pm 2.29$ \\
RC & $\mathbf{0 . 0 0 *}$ & & $\mathbf{0 . 0 0 *}$ & NS & NS & $6.93 \pm 1.71$ \\
\hline
\end{tabular}

Table 5. Multiple comparisons of RP scores according to the belonging department ( $\mathrm{p}$ value)

\begin{tabular}{lllllll}
\hline & NM & RC & RTH & RU & RA & score \\
\hline NM & & NS & NS & NS & $\mathbf{0 . 0 3 5}^{*}$ & $6.75 \pm 1.43$ \\
RTH & NS & NS & & NS & $\mathbf{0 . 0 3 5}^{*}$ & $6.70 \pm 0.96$ \\
RU & NS & NS & NS & & NS & $6.23 \pm 1.52$ \\
RA & $\mathbf{0 . 0 3 5 *}$ & NS & $\mathbf{0 . 0 3 5}^{*}$ & NS & & $5.36 \pm 1.82$ \\
RC & NS & & NS & NS & NS & $6.03 \pm 1.40$ \\
\hline
\end{tabular}


According to the training received in RP, the scores obtained for IR knowledge were better among workers who received training other than during the educational curriculum and among those who received training only during the educational curriculum (table 6). Regarding RP scores, workers who received no training had the lowest scores (table 7).

Table 6. Multiple comparisons of IR scores according to the training ( $\mathrm{p}$ value)

\begin{tabular}{lccccc}
\hline & No training & Only curriculum & $\begin{array}{c}\text { curriculum } \\
\text { +other }\end{array}$ & $\begin{array}{c}\text { Other } \\
\text { than curriculum }\end{array}$ & score \\
\hline No training & & $\mathbf{0 . 0 1 4 *}$ & 0.202 & $\mathbf{0 . 0 2 8 *}$ & $7.01 \pm 2.27$ \\
Only curriculum & $\mathbf{0 . 0 1 4 *}$ & & 0.404 & 0.798 & $8.1 \pm 1.91$ \\
Curriculum + other & 0.202 & 0.404 & & 0.364 & $7.68 \pm 1.51$ \\
Other than curriculum & $\mathbf{0 . 0 2 8 *}$ & 0.798 & 0.364 & & $8.23 \pm 0.86$ \\
\hline
\end{tabular}

Table 7. Multiple comparisons of RP scores according to the training ( $\mathrm{p}$ value)

\begin{tabular}{lccccc}
\hline & No training & Only curriculum & $\begin{array}{c}\text { curriculum } \\
\text { +other }\end{array}$ & $\begin{array}{c}\text { Other } \\
\text { than curriculum }\end{array}$ & score \\
\hline No training & & $\mathbf{0 . 0 0 0 *}$ & $\mathbf{0 . 0 0 0 *}$ & $\mathbf{0 . 0 0 1 *}$ & $4.82 \pm 1.49$ \\
\hline $\begin{array}{l}\text { Only curriculum } \\
\text { curriculum + other }\end{array}$ & $\mathbf{0 . 0 0 0 *}$ & & 0.40 & 0.94 & $6.62 \pm 1.38$ \\
Other than curriculum & $\mathbf{0 . 0 0 0 *}$ & 0.40 & & 0.28 & $7.21 \pm 1.84$ \\
\hline
\end{tabular}

In order to study the impact of knowledge in IR on the mastery of knowledge on principles and means of radiation protection, a linear regression was carried out. The correlation coefficient $\mathrm{R}^{2}$ was of 0.36 (figure 2).

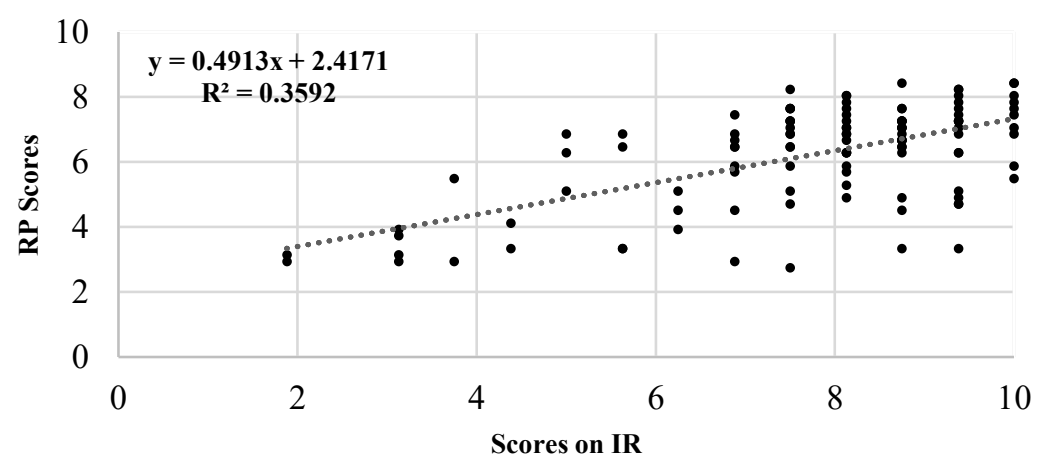

Fig. 2. Influence of IR knowledge on the acquisition of RP knowledge

The suggestions made by surveyed workers, in order to improve their own RP, mainly evoked the points summarized in table 8:

Table 8. Workers' expectations and needs

- Make personal dosimeters available and communicate the results to the workers

- Make always individual radiation protection resources available.

- Modernization of equipment and normative redevelopment of locals.

- Appoint a person responsible for radiation protection in all departments.

- Regular monitoring by an occupational physician. 


\section{Discussion}

Many studies carried out among medical workers about knowledge of IR and its uses, have aimed at a single category of workers or have been mainly interested in the RP concerning patients and how to inform them and advise them about IR exposition risks [6]-[8]. Most of these studies focused on one kind of radiation, usually X-rays, and were limited to a specific department [9] [10] [6] [7]. In the present study, worker radiation protection was targeted, and all UHCC medical and paramedical staff who daily use IR were surveyed. The questions addressed both the characteristics and effects of IR and the principles and means of RP.

Among the respondents, less than half (47.32\%) had a high level of overall knowledge (across all questions). This lack of knowledge is in agreement with numerous studies carried out on specialist doctors [6], [11], [12], or on interns and residents [13], [14] or even among all the staff of a department [15] [16] [17]. Although the structures targeted in these studies are not identical, the same conclusions are drawn: the knowledge of the medical personnel interviewed was overall insufficient.

We found that a large proportion of surveyed workers (74.11\%) had a high level of knowledge in IR and the average of their IRKS was quite good $(7.80 \pm 1.86)$. However, against all expectations, this good level in IR did not induce in the studied workers such a good knowledge of RP principles. In fact, only less than half (39\%) of the respondents had a good level of knowledge of RP, and the average RPKS was $6.23 \pm 1.52$ (table 2). Similar results have been found in other studies. For example, P. Ongolo-Zogo (2013) found that the level of knowledge in RP was good in $17 \%$ of the study population and J. Mbo Amvene (2017) in 40\% of surveyed population. Certainly, in our study the RPKS increases when the IRKS increases (figure 2), but there is a weak correlation between the two scores $\left(\mathrm{R}^{2}=0.36\right)$. This shows that a good knowledge of IR harmful effects is not sufficient, independently, to ensure a good mastery of RP principles and means. Basic learning of fundamental principles of radiation protection should be considered separately and in addition to the IR effects learning.

We found an inadequate level of knowledge also on IR and RP knowledge specific to such worker's home department. Only $56.25 \%$ of surveyed population had a high level. This result is below our expectations, as these knowledge are not generalities about RP and IR but intrinsic data to the daily task performed by the worker, and should be fully mastered. This finding should prompt managers to improve the knowledge of all staff of their respective departments to ensure them a safety work.

Unlike some studies [6], [9], [18], [19] we observed no influence of professional category or years of practice on any of calculated scores (table 3), especially on RPKS, which is the main object of our study. As residents and interns are numerous in our study population $(50 \%)$, one might think that they were at the origin of this low level of knowledge, because of their limited professional experience, but they had no statistically significant difference with their elders $(p=$ 0.45) (table 3). A standard basic radiation protection program, inadequate or not sufficiently efficient, that all physicians and health professionals received similarly could be the raison of this lack of knowledge.

Otherwise, the RPKS achieved by workers in nuclear medicine and radiation therapy departments were found to be relatively better with respect to other surveyed workers (table 5). In principle, all workers should give equal importance to their own protection regardless of the department to which they are belonging. However, this difference could be associated with the fact that in these departments, energy radiation sources used which have therapeutic purpose, are much higher than those predestined for diagnosis. Consequently, the possible exposure of workers to radiation could be more intense in the event of inadequate protection. Besides, nuclear medicine practitioners are often required to handle radiopharmaceuticals, which may come in unsealed form. These drugs, whose periods are often very long, present a high risk of contamination. Moreover, an external contamination with unsealed sources could be converted into an internal contamination via inhalation, ingestion or subcutaneous application. Furthermore, once the patient is kept in hospital, he presents a source of exposure for the medical staff. All this make the personal of these departments more radiation-cautious and better informed on the foundations and principles of radiation protection.

Nevertheless, the department to which medical staff belongs explains only $14 \%$ of the knowledge difference between departments $\left(\eta^{2}=0.140\right)$, compared to the influence of radiation protection training which has the strongest impact. Indeed, RP training explains $32 \%$ $\left(\eta^{2}=0.32\right)$ of the difference observed between groups that have gotten training whose the nature is different from one group to another ; knowledge was better acquired among professionals who received training compared to those who have never received training $(p \leq 0.001)$ (table 7). On the other hand, whether the training has been gotten, during the course or by another 
means, the observed difference in scores was not significant. One can accordingly ask some questions about the key role and the efficiency of training during the university course. This training should be the guarantor of a good acquisition of basic knowledge that is necessary to work safely in all medical fields in which the medical staff handles radioactive substances. Is it relevant? Is it sufficient?

In accordance with the directives of official organizations (IAEA, ICRP, Moroccan law, etc.), a training in radiation protection should be vital for all medical personnel that might be exposed to ionizing radiations. However, in our study, a quarter of the population (nurses, interns and residents and technicians) have reported that they have never attended an education on radiation protection (table 1). This lack of RP training is not exclusive in Morocco, other researches on radiation safety knowledge have found proportions of untrained health workers in RP, ranging from 27 to $35 \%$ [15] [20] and the level of knowledge was significantly correlated with the lack of training in this area.

Apart from that, as we have noticed, the academic training in radiation protection was not sufficient, since it seems to provide workers with RP skills equivalent to those of any other non-academic training (self-training, pre-hire training). The basic training should be accordingly reinforced, and updated through a continuing training assured by a person responsible for radiation protection and renewed regularly each three years, according to international recommendations. In the present study, only a minority $(5 \%)$ of participants reported that they have taken advantage of such training (table 1), the same observation was made in other countries where continuing training in hospitals was rare or even non-existent [15] [19] [21]. If the majority (76.78\%) of participants expressed the desire to benefit (table 1), the remaining participants, that are not negligible, did not see the usefulness of such training. This fact shows that there is still a huge ignoring of the gravity of ionizing radiation effects.

Moreover, the workers in our study expressed some shortcomings in relation to devices necessary for safety at work, in their respective departments. Particularly concerning the equipment and coaching (table 8), which are supposed to improve their radiation protection, make them aware of IR dangers and develop at them the knowledge necessary to achieve this. This is partly because of Moroccan law, until then, was not precise about neither the modalities of an eventual continuing training nor the obligation to have a competent person in radiation protection, in all departments previously mentioned, to identify radiation safety problems and ensure continuing training and compliance with regulations.

At the time of writing this paper, the AMSSNuR, which is a strategic public establishment, in its draft decree implementing the 142-12 law on the protection of workers, public and environment against ionizing radiation [22], has established new legal texts that manage, among other things, the training of workers and ensure their implementation. These laws require that the information of personnel exposed to IR on the risks of this exposure and their training on radiation protection are mandatory and provided by the employer, while specifying their terms. In the next years we could as a perspective, contemplate to repeat a similar study in order to assess the impact of the application of these new legal texts on the level of knowledge of workers that handle radioactive substances in their departments.

\section{Strengths and limits of this study:}

The response rate was $83 \%$ so the survey covered all departments belonging to the UHCC that daily use IR and all their medical staff. The sample is accordingly representative and brings accuracy regarding drawn deductions. We also assessed knowledge of IR and RP separately to properly target where the lack is.

The major drawback was, as all studies based on a questionnaire, an overestimation of the level of knowledge since it was not possible to ensure that the answers were personal. We have tried to overcome this bias, as much as possible by shortening the period given to surveyed people so that they fill the questionnaire. On the other hand, the comparison with other studies could be biased considering that targeted departments and professional categories are not similar for all studies, moreover, there is no standard and validated questionnaire, in Arabic or in French, which would ensure a homogenous evaluation of knowledge in this field. However, efforts are made by some researchers in order to develop and validate psychometric scales [23], that it would be interesting and useful to adapt in French for similar earlier study.

\section{Conclusion}

The present study showed that the medical staff of UHCC has an insufficient level of knowledge on workers radiation protection. Occupational category and years of practice have no influence on this lack of knowledge. On the other hand, the department of belonging, and even more the radiation protection training received by the participants, have a significant impact. In order to fill this gap, it would be wise to 
improve the medical educational curriculum regarding radiation protection, set up systematic pre-hire training, integrate obligatorily continuing training on radiation protection into every department that works with IR and make sure that a person responsible for radiation protection provides this training.

Keywords: workers' health, Radiation protection, ionizing radiation, knowledge, Ibn Rochd UHC of Casablanca

\section{Conflicts of interest:}

The authors state that there is no conflict of interest associated with this study.

\section{References}

1. «IRSN_Rapport-Exposition-travailleurs2017.pdf ». Consulté le: mai 17, 2021. [En ligne]. Disponible sur: https://www.irsn.fr/FR/expertise/ rapports_expertise/Documents/radioprotection/IR SN_Rapport-Exposition-travailleurs-(2017).pdf

2. «Les principes de radioprotection - ASN ». https://www.asn.fr/Informer/Publications/Fichesd-information-du-public/Les-principes-deradioprotection (consulté le mai 17, 2021).

3. Y. S. Cordiolani, Radioprotection en milieu médical: principes et pratiques (ELSEVIERMASSON 2008).

4. « Rayonnements ionisants. Exposition aux risques - Risques - INRS ».

https://www.inrs.fr/risques/rayonnementsionisants/exposition-aux-risques (consulté le 17 mai 17, 2021).

5. « Présentation », AMSSNuR. https://amssnur.org.ma/vision-presentationamssnur/ (consulté le mai 17, 2021).

6. D. Macía-Suárez et E. Sánchez-Rodríguez, « Radiation protection knowledge among radiologists in northwest Spain », Radiol. Engl. Ed., 60, no 4, p. 318-323, juill. (2018), doi: 10.1016/j.rxeng.2018.01.001.

7. M. Günalp et al., « Ionising radiation awareness among resident doctors, interns, and radiographers in a university hospital emergency department $»$, Radiol. Med. (Torino), 119, $\mathrm{n}^{\circ}$ 6, p. 440-447, juin (2014), doi: 10.1007/s11547-013-0374-8.

8. D. Zewdneh, «A Study of Knowledge \& Awareness of Medical Doctors Towards Radiation Exposure Risk At Tikur Anbessa Specialized Referral And Teaching Hospital, Addis Ababa, Ethiopia. », IOSR J. Pharm. Biol. Sci., 2, no 4, p. 1-5, (2012), doi: 10.9790/3008-0240105.

9. M. Hammamia et al., «Connaissances du personnel de chirurgie endovasculaire en radioprotection », JMV-J. Médecine Vasc., 43, mai (2018), doi: 10.1016/j.jdmv.2018.05.001.
10. F. Shabani et al., « Radiation Protection Knowledge, Attitude, and Practice (KAP) in Interventional Radiology », Oman Med. J., 33, $\mathrm{n}^{\circ}$ 2, p. 141-147, mars (2018), doi: 10.5001/omj.2018.26.

11. A. Finestone, T. Schlesinger, H. Amir, E. Richter, et C. Milgrom, « Do Physicians Correctly Estimate Radiation Risks from Medical Imaging? », Arch. Environ. Health Int. J., 58, $\mathrm{n}^{\circ}$ 1, p. 59-62, janv. (2003), doi: 10.3200/AEOH.58.1.59-62.

12. A. Yurt, B. Çavuşoğlu, et T. Günay, « Evaluation of Awareness on Radiation Protection and Knowledge About Radiological Examinations in Healthcare Professionals Who Use Ionized Radiation at Work », Malecular Imaging Radionucl. Ther., 22, no 2, p. 48-53, juin (2014), doi: 10.4274/mirt.00719.

13. S. Salerno et al., « Radiation risks knowledge in resident and fellow in paediatrics: a questionnaire survey ", Ital. J. Pediatr., 41, $\mathrm{n}^{\circ}$ 1, p. 21, déc. (2015), doi: 10.1186/s13052-015-0130-x.

14. G. Sadigh, R. Khan, M. T. Kassin, et K. E. Applegate, « Radiation Safety Knowledge and Perceptions among Residents », Acad. Radiol., 21, $\mathrm{n}^{\mathrm{o}} 7$, p. 869-878, juill. (2014), doi: 10.1016/j.acra.2014.01.016.

15. P. Ongolo-Zogo, M. B. Nguehouo, J. Yomi, et S. Nko'o Amvene, "Connaissances en matière de radioprotection : enquête auprès des personnels des departments hôspitaliers de radiodiagnostic, radiothérapie et médecine nucléaire a Yaoundé Cameroun », Radioprotection, 48, p. 39-49, janv. (2012), doi: 10.1051/radiopro/2012017.

16. D. Akanni et al., « Connaissances en radioprotection des travailleurs exposés aux rayonnements ionisants en milieu médical en Afrique francophone subsaharienne », Radioprotection, 56, $\mathrm{n}^{\mathrm{o}} 1$ (2021). https://doi.org/10.1051/radiopro/2020067

17. W. Chun-sing, H. Bingsheng, S. Ho-kwan, W. Wailam, Y. Ka-ling, et C. Y. C. Tiffany, «A questionnaire study assessing local physicians, radiologists and interns' knowledge and practice pertaining to radiation exposure related to radiological imaging », Eur. J. Radiol., 81, n 3, p. e264-e268, $\operatorname{mars}(2012), \quad$ doi: 10.1016/j.ejrad.2011.02.022.

18. I. Marzouk Moussa et H. Kamoun, "Connaissances des travailleurs en radioprotection - Enquête au CHU Mongi Slim à La Marsa (Tunisie) », Radioprotection, 51, n 2, p. 123-128, avr. (2016), doi: $10.1051 /$ radiopro/2015034. 
19. F. Kouandongui Bangue Songrou, E. Bidan Tapiade, M. Ouimon, et T. Mobima, «Connaissances en matière de radioprotection des manipulateurs de radiologie de Bangui et de Bimbo (Centrafrique) », Radioprotection, 54, $\mathrm{n}^{0}$ 1, $\mathrm{p}$. 41-45, janv. (2019), doi: 10.1051/radiopro/2018046.

20. L. Hirvonen et al., « Nurses' knowledge of radiation protection: A cross-sectional study », Radiography, 25, mai (2019), doi: 10.1016/j.radi.2019.04.011.

21. J. M. Amvene, B. Djonyang, J. M. Amougou, D. Ngaroua, et S. N. Amvene, "Observance des Règles de Radioprotection dans les Departments d'Imagerie des Hôpitaux de l'Extrême-Nord du Cameroun », Health Sci. Dis., 18, no 2, Art. no 2, avr. (2017), Consulté le: mai 30, 2021. [En ligne]. Disponible sur : https://www.hsdfmsb.org/index.php/hsd/article/view/824

22. http://www.sgg.gov.ma/portals/0/ AvantProjet/198/Avp dec 2.20.146 Fr.pdf

23. T. Schroderus-Salo et al., « Development and validation of a psychometric scale for assessing healthcare professionals' knowledge in radiation protection $»$, Radiography, 25, mai (2019), doi: 10.1016/j.radi.2018.12.010. 